Article

\title{
Evaluating Impacts of Different Omega-6 to Omega-3 Fatty Acid Ratios in Corn-Soybean Meal-Based Diet on Growth Performance, Nutrient Digestibility, Blood Profiles, Fecal Microbial, and Gas Emission in Growing Pigs
}

\author{
Dinh Hai Nguyen, Hyeok Min Yun and In Ho Kim * \\ Department of Animal Resource and Science, Dankook University, Cheonan-si, Chungnam 31116, Korea; \\ nguyenhaibg90@gmail.com (D.H.N.); yunhm822@naver.com (H.M.Y.) \\ * Correspondence: inhokim@dankook.ac.kr; Tel.: +82-41-550-3652; Fax: +82-41-559-7881
}

Received: 3 November 2019; Accepted: 20 December 2019; Published: 24 December 2019

Simple Summary: There are two major classes of polyunsaturated fatty acids found in the diet, omega- 3 and omega-6, these polyunsaturated fatty acids are essential because they cannot be synthesized by humans and animals. Also, they cannot be converted into each other in the body. Supplementation of omega-3 has been reported to improve the performance and health of pigs. However, during the past years, studies had demonstrated that animal performance could be influenced by the dietary level or the ratio of omega- 6 and omega- 3 . A high omega-6: omega- 3 ratio in diets promotes the pathogenesis of many diseases, including cardiovascular disease, cancer, and inflammatory and autoimmune diseases. An optimal omega-6: omega-3 ratio could inhibit immune stimulation to ensure the availability of more energy and nutrients for high performance and the homeostatic pathway. The present study investigated the effects of different omega-6: omega-3 ratios (17:1, 15:1, 10:1, 5:1) on growth performance, nutrient digestibility, blood profiles, fecal microflora, and gas emission in growing pigs. The results of this study showed that reducing omega-6: omega-3 ratio from 17:1 to 5:1 by increasing omega-3 in the diet increased body weight, energy digestibility, and reduced the low-density lipoprotein concentrations of blood in growing pigs.

Abstract: This study was conducted to evaluate the effect of different omega-6: omega-3 fatty acid (FA) ratios in a corn-soybean meal-based diet in growing pigs. A total of 140 [Duroc $\times$ (Landrace $\times$ Yorkshire)] growing pigs with an average body weight (BW) of $24.75 \pm 1.43 \mathrm{~kg}$ were used in a 6-week trial. Pigs were allocated randomly into one of four treatments according to sex and BW (seven replications with five pigs per pen). The treatment groups consisted of 4 diets with omega-6:omega-3 FA ratios of 17:1, 15:1, 10:1, and 5:1. In the current study, the energy digestibility, BW, and average daily gain $(A D G)$ increased $(p<0.05)$ in pigs provided with the 5:1 diet compared to pigs fed the 17:1 diet in the sixth week. The low-density lipoprotein (LDL) concentrations of blood were lower $(p<0.05)$ in pigs fed the 5:1 diet compared to the 17:1 and 15:1 diet. However, the fecal microflora and fecal gas emissions were unaffected $(p>0.05)$ by the different omega-6: omega-3 FA ratios in diets. In conclusion, reducing omega-6: omega-3 ratio by increasing omega-3 in diet improved BW, $\mathrm{ADG}$, and gross energy digestibility, and reduced the LDL concentrations of blood in growing pigs.

Keywords: blood profile; fecal gas emission; fecal microbial; nutrient digestibility; omega-6: omega-3 fatty acids; growth performance 


\section{Introduction}

There are two major classes of polyunsaturated fatty acids (PUFA) found in the diet, omega-3, and omega-6, which are essential but cannot be synthesized by humans and animals as well as cannot be transformed one to another in the body [1,2]. Hence, PUFA are crucial components of the food or diet. Beneficial effects of additions of essential fatty acids (FA) to diets fed to animals have been reported. Previous studies indicated that consuming omega-3 FA improved the health status of weanling pigs that are faced with different stressors due to their effects on the immune system [3,4]. Similarly, Upadhaya et al. indicated that providing omega-3 FA to pigs could improve performance and their health $[5,6]$.

Studies have demonstrated that sow and cockerel performance could be influenced by the level or the ratio of omega- 6 and omega-3 PUFA [7,8]. Simopoulos observed that in humans, the higher the ratio of omega-6: omega-3 FA in platelet phospholipids, the higher the death rate from cardiovascular disease. A high omega-6:omega-3 FA ratio in diets promotes the pathogenesis of many diseases, including cardiovascular disease, cancer, and inflammatory and autoimmune diseases [2]. Moreover, there exists a competition between the 18-carbon omega-3 and omega-6 FA because they share a common enzymatic pathway in the synthesis of their longer chain derivatives. Thus, the dietary ratio of omega-3 and omega-6 FA may be important to maximize the benefits of adding omega-3 FA into diets [9]. An optimal omega-6:omega-3 FA ratio could inhibit immune stimulation to provide more energy and nutrients for optimum performance and homeostatic pathways [10,11]. Previous reports showed that a diet with a lower omega-6:omega-3 PUFA ratio, rich in omega-3 PUFA, is beneficial for the growth performance and health of avian [12-14].

The costs of feed play a major role in determining the profitability of a pig producer because it represents up to $70 \%$ of the variable costs of swine production [15]. However, increasing the levels of omega-3 FA to reduce the ratio of omega-6: omega-3 FA may increase the cost of the feed. Thus, studies are focused to find techniques to enhance the effective delivery of omega-3 FA to appropriate sites in the body for absorption as well as reduce feed cost and extract more nutrients from feed ingredients. Nguyen et al. reported that the effectiveness of organic acids could be enhanced by matrix coating or encapsulation techniques to protect OAs for targeted delivery to different gut segments has gained considerable attention [16]. We hypothesize that using a coated omega-3 FA may also enhance the effective absorption, metabolism of omega-3 FA, and thus stimulate their modulatory effect on the large intestinal microbiota.

The object of the current study was to examine effects of different omega-6:omega-3 FA ratios $(17: 1,15: 1,10: 1,5: 1)$ in corn-soybean meal-based diets on growth performance, nutrient digestibility, blood profiles, fecal microflora, and gas emission in growing pigs.

\section{Materials and Methods}

The experimental protocol used in this study was approved by the Animal Care and Use Committee of Dankook University.

\subsection{Source of Omega-3 FA}

The omega-3 FA used in this study was provided by a commercial company (Morningbio Co., Ltd., Cheonan, Korea). It was produced from linseed oil and refined fish oil and was protected using matrix coating technology. According to the information provided by the supplier, the omega- 3 and omega-6 PUFA contents were $17.8 \%$ and $4.7 \%$ of dry matter, respectively.

\subsection{Experimental Design, Animals, and Diets}

A total of 140 [Duroc $\times($ Landrace $\times$ Yorkshire)] growing pigs with an average body weight (BW) of $24.75 \pm 1.43 \mathrm{~kg}$ were used in a 6-week trial. Pigs were allocated randomly into one of four treatments according to sex and BW, providing seven replicates with two gilts and three barrows per 
pen. The treatment groups consisted of four diets with omega-6:omega-3 FA ratios of 17:1, 15:1, 10:1, and 5:1. Diets were formulated to meet or exceed NRC recommendations for all nutrients (Table 1). The analyzed fatty acid profile of the experimental diets were shown in the Table 2. Pigs were housed in an environmentally controlled room with a slatted plastic floor [17]. Throughout the experiment, all pigs were provided with ad libitum access to feed and water through a self-feeder and nipple drinker, respectively. Target room temperature and humidity were $25 \pm 1^{\circ} \mathrm{C}$ and around $60 \%$, respectively.

Table 1. Composition of basal diets (as-fed basis)

\begin{tabular}{|c|c|c|c|c|}
\hline \multirow{2}{*}{ Items } & \multicolumn{4}{|c|}{ Dietary Treatment (Omega-6: Omega-3 Ratio) } \\
\hline & $17: 1$ & 15:1 & 10:1 & $5: 1$ \\
\hline \multicolumn{5}{|c|}{ Ingredients (\%) } \\
\hline Corn & 66.90 & 66.94 & 66.99 & 67.14 \\
\hline Soybean meal & 23.69 & 23.66 & 23.65 & 23.62 \\
\hline Tallow & 3.11 & 3.06 & 2.78 & 1.94 \\
\hline Molasses & 3.00 & 3.00 & 3.00 & 3.00 \\
\hline Limestone & 1.18 & 1.18 & 1.18 & 1.18 \\
\hline Monodicalcium phosphate & 0.93 & 0.93 & 0.93 & 0.93 \\
\hline Salt & 0.40 & 0.40 & 0.40 & 0.40 \\
\hline L-Met 98\% & 0.05 & 0.05 & 0.05 & 0.05 \\
\hline L-Lys 78\% & 0.32 & 0.32 & 0.32 & 0.32 \\
\hline L-Thr 98.5 & 0.10 & 0.10 & 0.10 & 0.10 \\
\hline L-Trp 98\% & 0.10 & 0.10 & 0.10 & 0.10 \\
\hline Vitamin-Mineral Premix ${ }^{a}$ & 0.20 & 0.20 & 0.20 & 0.20 \\
\hline Choline & 0.02 & 0.02 & 0.02 & 0.02 \\
\hline Omega-3 fatty acid & 0.00 & 0.04 & 0.28 & 0.99 \\
\hline \multicolumn{5}{|c|}{ Calculated composition, $\%$} \\
\hline ME, kcal & 3350 & 3350 & 3350 & 3350 \\
\hline Crude protein & 16.00 & 16.00 & 16.00 & 16.00 \\
\hline Crude fat & 5.63 & 5.62 & 5.53 & 5.25 \\
\hline Crude fiber & 2.89 & 2.89 & 2.89 & 2.89 \\
\hline Crude ash & 4.42 & 4.42 & 4.42 & 4.42 \\
\hline $\mathrm{Ca}$ & 0.66 & 0.66 & 0.66 & 0.66 \\
\hline Total phosphorus & 0.51 & 0.51 & 0.51 & 0.51 \\
\hline Available P & 0.26 & 0.26 & 0.26 & 0.26 \\
\hline SID lysine & 0.98 & 0.98 & 0.98 & 0.98 \\
\hline SID methionine & 0.28 & 0.28 & 0.28 & 0.28 \\
\hline Methionine + cystine & 0.56 & 0.51 & 0.51 & 0.51 \\
\hline Threonine & 0.59 & 0.59 & 0.59 & 0.59 \\
\hline Tryptophan & 0.17 & 0.17 & 0.17 & 0.17 \\
\hline
\end{tabular}

a Provided per kg of complete diet: $8000 \mathrm{IU}$ vitamin A, $800 \mathrm{IU}$ vitamin D3, 40 IU vitamin E, $2.0 \mathrm{mg}$ vitamin K, $4.0 \mathrm{mg}$ vitamin B6, $3.0 \mathrm{mg}$ vitamin B12, $20 \mu \mathrm{g}$ pantothenic acid, $15 \mathrm{mg}$ niacin, and $0.02 \mathrm{mg}$ biotin; $150 \mathrm{mg} \mathrm{Cu} 150 \mathrm{mg}$ Fe, 50 $\mathrm{mg} \mathrm{Zn}, 0.5 \mathrm{mg} \mathrm{I}, 0.5 \mathrm{mg} \mathrm{Co}$, and $0.3 \mathrm{mg}$ Se.

Table 2. Analyzed fatty acid profile of the experimental diets.

\begin{tabular}{ccccc}
\hline \multirow{2}{*}{ Items } & \multicolumn{3}{c}{ Dietary Treatment (Omega-6: omega-3 Ratio) } \\
\cline { 2 - 5 } & $\mathbf{1 7 : 1}$ & $\mathbf{1 5 : 1}$ & $\mathbf{1 0 : 1}$ & $\mathbf{5 : 1}$ \\
\hline C13:0, \% & 0.56 & 0.61 & 0.25 & 0.42 \\
C14:0, \% & 1.40 & 1.32 & 1.08 & 0.78 \\
C15:0, \% & 0.29 & 0.27 & 0.24 & 0.00 \\
C16:0, \% & 20.84 & 21.08 & 21.07 & 22.03 \\
C18:0, \% & 8.48 & 8.91 & 10.83 & 11.83 \\
C18:1, \% & 37.67 & 36.74 & 35.72 & 31.86 \\
Omega-3 (linoleic acid), \% & 28.74 & 28.53 & 27.80 & 26.59 \\
Omega-6 ( $\alpha$-linolenic acid), \% & 1.67 & 1.84 & 2.77 & 5.32 \\
Docosahexaenoic acid, \% & 0.00 & 0.00 & 0.00 & 0.41 \\
Saturated fatty acid, \% & 31.57 & 32.19 & 33.46 & 35.06 \\
Monounsaturated fatty acid, \% & 37.67 & 36.74 & 35.72 & 31.86 \\
Polyunsaturated fatty acid, \% & 30.41 & 30.37 & 30.57 & 32.32 \\
Omega-6: omega-3 ratio, \% & 17.21 & 15.51 & 10.04 & 4.64 \\
\hline
\end{tabular}




\subsection{Sampling and Measurements}

Individual pigs' BW and feed intake were measured initially and the end of week 6 and feed consumption was recorded on a pen basis during the experiment to determine average daily gain (ADG), average daily feed intake (ADFI), and gain to feed ratio (G: F).

Chromium oxide was added to the diet as an indigestible marker at $0.20 \%$ of the diet for seven days prior to fecal collection at the end of week 6 for calculation of dry matter (DM), nitrogen (N), and gross energy digestibility. Fecal grab samples were collected at random from two pigs (one gilt and one barrow) from each pen and were mixed and pooled, and a representative sample was stored in a freezer at $-20^{\circ} \mathrm{C}$ until analysis. Fecal samples were dried at $70{ }^{\circ} \mathrm{C}$ for $72 \mathrm{~h}$ and finely ground to pass through a 1-mm screen. All feed and fecal samples were analyzed for DM (method 930.15) and crude protein (N 9 6.25; method 984.13) [18]. Gross energy was determined by measuring the heat of combustion in the samples, using a bomb calorimeter (Parr 6100; Parr Instrument Co., Moline, IL, USA). Chromium was analyzed via UV absorption spectrophotometry (Shimadzu UV-1201; Shimadzu, Kyoto, Japan). The apparent total tract digestibility (ATTD) was then calculated using the following formula: Digestibility $(\%)=\{1-[(\mathrm{Nf} \times \mathrm{Cd}) /(\mathrm{Nd} \times \mathrm{Cf})]\} \times 100$ Where: $\mathrm{Nf}=$ nutrient concentration in feces $(\% \mathrm{DM}), \mathrm{Nd}=$ nutrient concentration in $\operatorname{diet}(\% \mathrm{DM}), \mathrm{Cf}=$ chromium concentration in feces $(\%$ $\mathrm{DM}), \mathrm{Cd}=$ chromium concentration in feces (\% DM).

Two pigs (one barrow and one gilt) were randomly selected from each pen and bled via jugular venipuncture at the end of the experiment (14 pigs per treatment). Blood samples ( $3 \mathrm{~mL}$ ) were collected into vacuum tubes (containing no additive) (Becton Dickinson Vacutainer Systems, Franklin Lakes, NJ, USA) to obtain serum. The concentrations of triglyceride, total cholesterol, high-density lipoprotein (HDL) cholesterol, and low-density lipoprotein (LDL) cholesterol in the serum samples were analyzed with an automatic biochemical analyzer (RA-1000, Bayer Corp., Tarrytown, NY, USA) using the colorimetric method.

At the end of the experiment, fecal samples were collected directly via massaging the rectum of 2 pigs ( 1 gilt and 1 barrow) in each pen (14 pigs per treatment) and then pooled and placed on ice for transportation to the laboratory where analysis was immediately performed. Samples were diluted with deionized water at a ratio of 1:7.5 (w/w). One gram of the composite fecal sample from each pen was diluted with $9 \mathrm{~mL}$ of $1 \%$ peptone broth (Becton, Dickinson and Co., Franklin Lakes, USA) and then homogenized. Viable counts of bacteria in the fecal samples were then conducted by plating serial 10-fold dilutions (in 1\% peptone solution) onto MacConkey agar plates (Difco Laboratories, Detroit, MI, USA) and Lactobacilli medium III agar plates (Medium 638; DSMZ, Braunschweig, Germany) to isolate the E. coli and Lactobacillus, respectively. The Lactobacilli medium III agar plates were then incubated for $48 \mathrm{~h}$ at $39{ }^{\circ} \mathrm{C}$ under anaerobic conditions. The MacConkey agar plates were incubated for $24 \mathrm{~h}$ at $37^{\circ} \mathrm{C}$. The E. coli and Lactobacillus colonies were counted immediately after removal from the incubator.

Fresh feces and urine samples were collected randomly from at least two pigs in each pen during the last 2 days of the end of the experiment. The urine was collected in a bucket via a funnel below the pen. Samples were kept in sealed containers and were immediately stored at $-4{ }^{\circ} \mathrm{C}$ for the duration of the collection period. After the collection period, feces and urine samples were pooled and each mixed well for each pen. As described by Wang et al., subsamples of the slurry (150 $\mathrm{g}$ feces and $150 \mathrm{~g}$ of urine were mixed well; 1:1 on the wet weight basis) were taken and stored in 2.6-L plastic boxes in duplicate [19]. Each box had a small hole in the middle of one sidewall, which was sealed with adhesive plaster. The samples were permitted to ferment for $7 \mathrm{~d}$ at room temperature $\left(25^{\circ} \mathrm{C}\right)$. The concentrations of gas were determined on d 7. A gas sampling pump (Model GV-100; Gastec Corp., Ayase, Japan) was utilized for gas detection (Gastec detector tube No. 3La for ammonia $\left(\mathrm{NH}_{3}\right)$, No. $4 \mathrm{LK}$ for hydrogen sulfide $\left(\mathrm{H}_{2} \mathrm{~S}\right)$, and No. 70 for mercaptans; Gastec Corp.). 


\subsection{Statistical Analysis}

The pen was used as the experiment unit and all data were subjected to statistical analysis using the GLM procedures of SAS as a randomized complete block design (SAS Institute Inc., Cary, NC, USA) [20]. Differences among all treatments were separated by Turkey's multiple range test. A probability level of $p<0.05$ was considered to be statistically significant.

\section{Results}

\subsection{Growth Performance}

In the current study, pigs fed the 5:1 diet had increased $(p<0.05)$ final body weight due to greater $(p=0.04)$ ADG compared to pigs fed the 17:1 diet at the end of the experiment (Table 3$)$. There were no significant effects $(p>0.05)$ observed in ADFI and G: F during the whole experimental period among four treatments.

Table 3. Effect of omega-6: omega-3 fatty acid ratio on growth performance in growing pigs

\begin{tabular}{|c|c|c|c|c|c|c|}
\hline \multirow{2}{*}{ Items } & \multicolumn{4}{|c|}{ Dietary Omega-6: omega-3 Fatty Acid Ratio } & \multirow{2}{*}{ SEM } & \multirow{2}{*}{$p$-Value } \\
\hline & 17:01 & 15:1 & 10:1 & $5: 1$ & & \\
\hline \multicolumn{7}{|c|}{ Body weight, $\mathrm{kg}$} \\
\hline Initial & 24.75 & 24.76 & 24.74 & 24.74 & 0.01 & 0.17 \\
\hline Day 42 & $54.27^{\mathrm{b}}$ & $54.83^{\mathrm{ab}}$ & $55.29 \mathrm{ab}$ & $55.83^{\mathrm{a}}$ & 0.36 & 0.04 \\
\hline \multicolumn{7}{|l|}{ Overall } \\
\hline ADG, $g$ & $703^{b}$ & $716^{\mathrm{ab}}$ & $727^{a b}$ & $740^{\mathrm{a}}$ & 8.70 & 0.04 \\
\hline ADFI, $g$ & 1626 & 1637 & 1661 & 1656 & 19.37 & 0.56 \\
\hline $\mathrm{G}: \mathrm{F}$ & 0.433 & 0.437 & 0.438 & 0.447 & 0.01 & 0.28 \\
\hline
\end{tabular}

${ }^{1}$ Dietary treatments were different ratio of omega-6:omega-3 fatty acid, including 17:1, 15:1, 10:1, and 5:1, SEM: standard error of means, ADG: average daily gain, ADFI: average daily feed intake, G:F: gain to feed ratio, ${ }^{a, b}$ means in the same row with different superscript differ significantly $(p<0.05)$.

\subsection{Nutrient Digestibility}

The digestibility of energy in the 5:1 treatment increased $(p>0.05)$ compared to pigs fed the 17:1 diet in the sixth week (Table 4$)$. No differences $(p>0.05)$ were observed in the digestibility of DM and $\mathrm{N}$ among four treatments at the end of the experiment.

Table 4. Effect of omega-6: omega-3 fatty acid ratio on nutrient digestibility in growing pigs

\begin{tabular}{ccccccc}
\hline \multirow{2}{*}{ Items, \% } & \multicolumn{7}{c}{ Dietary Omega-6: omega-3 Fatty Acid Ratio } & \multirow{2}{*}{ SEM } & $p$-Value \\
\cline { 2 - 4 } & $\mathbf{1 7 : 0 1}$ & $\mathbf{1 5 : 1}$ & $\mathbf{1 0 : 1}$ & $\mathbf{5 : 1}$ & & \\
\hline Day 42 & \multicolumn{7}{c}{} & & \\
\hline Dry matter & 77.26 & 77.07 & 78.49 & 77.88 & 0.74 & 0.89 \\
Nitrogen & 76.02 & 75.53 & 77.72 & 78.19 & 0.86 & 0.70 \\
Energy & $76.93^{\mathrm{b}}$ & $76.88^{\mathrm{b}}$ & $78.48^{\mathrm{ab}}$ & $78.64^{\mathrm{a}}$ & 0.46 & 0.03 \\
\hline
\end{tabular}

Dietary treatments were different ratio of omega-6: omega-3 fatty acid, including 17:1, 15:1, 10:1, and 5:1, SEM: standard error of means, ${ }^{a, b}$ means in the same row with different superscript differ significantly $(p<0.05)$.

\subsection{Blood Profiles}

The HDL, triglyceride and total cholesterol concentrations were not affected $(p>0.05)$ by treatments, but the LDL concentrations were decreased $(p<0.05)$ in the 5:1 treatment compared to the 17:1 and 15:1 treatment at the end of the experiment (Table 5). 
Table 5. Effect of omega-6: omega-3 fatty acid ratio on blood profile in growing pigs

\begin{tabular}{ccccccc}
\hline \multirow{2}{*}{ Items, $\mathbf{~ m g / d L ~}$} & \multicolumn{7}{c}{ Dietary Omega-6: Omega-3 Fatty Acid Ratio } & \multirow{2}{*}{ SEM } & p -Value \\
\cline { 2 - 5 } & $\mathbf{1 7 : 0 1}$ & $\mathbf{1 5 : 1}$ & $\mathbf{1 0 : 1}$ & $\mathbf{5 : 1}$ & & \\
\hline HDL & 38 & 41 & 44 & 45 & 3.24 & 0.46 \\
LDL & $59^{\mathrm{a}}$ & $54^{\mathrm{a}}$ & $52^{\mathrm{ab}}$ & $46^{\mathrm{b}}$ & 1.98 & 0.01 \\
Triglyceride & 46 & 45 & 42 & 40 & 3.27 & 0.50 \\
Total cholesterol & 119 & 114 & 117 & 118 & 4.89 & 0.88 \\
\hline
\end{tabular}

Dietary treatments were different ratio of omega-6: omega-3 fatty acid, including 17:1, 15:1, 10:1, and 5:1, SEM: standard error of means, HDL: high-density lipoprotein, LDL: low-density lipoprotein, ${ }^{\mathrm{a}, \mathrm{b}}$ means in the same row with different superscript differ significantly $(p<0.05)$.

\subsection{Fecal Microflora and Fecal Noxious Gas Content}

The fecal microflora (Lactobacillus and E. coli) and fecal gas emission $\left(\mathrm{NH}_{3}\right.$, total mercaptans, and $\mathrm{H}_{2} \mathrm{~S}$ ) were unaffected $(p>0.0 .5)$ by treatments at the end of the experiment (Tables 6 and 7).

Table 6. Effect of omega-6: omega-3 fatty acid ratio on fecal microbial population in growing pigs

\begin{tabular}{ccccccc}
\hline \multirow{2}{*}{ Items, $\log _{\mathbf{1 0}} \mathbf{c f u} / \mathbf{g}$} & \multicolumn{2}{c}{ Dietary } & Omega-6: Omega-3 Fatty Acid Ratio & \multirow{2}{*}{ SEM } & $\boldsymbol{p}$-Value \\
\cline { 2 - 5 } & $\mathbf{1 7 : 0 1}$ & $\mathbf{1 5 : 1}$ & $\mathbf{1 0 : 1}$ & $\mathbf{5 : 1}$ & & \\
\hline Day 42 & & & & & & \\
\hline Lactobacillus & 7.37 & 7.41 & 7.45 & 7.50 & 0.05 & 0.39 \\
E. coli & 5.90 & 5.89 & 5.89 & 5.86 & 0.07 & 0.97 \\
\hline
\end{tabular}

Dietary treatments were different ratio of omega-6: omega-3 fatty acid, including 17:1, 15:1, 10:1, and 5:1, SEM: standard error of means.

Table 7. Effect of omega-6: omega-3 fatty acid ratio on fecal gas-emission in growing pigs

\begin{tabular}{ccccccc}
\hline \multirow{2}{*}{ Items, ppm } & \multicolumn{7}{c}{ Dietary Omega-6: omega-3 Fatty Acid Ratio } & \multirow{2}{*}{ SEM } & $p$-Value \\
\cline { 2 - 4 } & $\mathbf{1 7 : 0 1}$ & $\mathbf{1 5 : 1}$ & $\mathbf{1 0 : 1}$ & $\mathbf{5 : 1}$ & \\
\hline \multicolumn{7}{c}{ Week 6 } \\
\hline Total mercaptans & 4.75 & 4.40 & 4.33 & 0.66 & 0.95 \\
$\mathrm{HH}_{2} \mathrm{~S}$ & 3.15 & 2.90 & 2.80 & 2.85 & 0.43 & 0.94 \\
& 3.50 & 3.18 & 3.33 & 3.20 & 0.70 & 0.99 \\
\hline
\end{tabular}

Dietary treatments were different ratio of omega-6: omega-3 fatty acid, including 17:1, 15:1, 10:1, and 5:1, SEM: standard error of means, $\mathrm{NH}_{3}$ : ammonia, $\mathrm{H}_{2} \mathrm{~S}$ : hydrogen sulfide.

\section{Discussions}

Long-chain omega-3 PUFAs from fish oil are known to improve insulin-mediated glucose metabolism in insulin-resistant states [21,22]. The potential role in regulating insulin-mediated protein metabolism was investigated by Gingras et al., who postulated that incorporation of long-chain omega-3 PUFA into muscle membrane phospholipids of steers would enhance the sensitivity of the muscle to insulin, promote protein anabolism by reducing catabolic pathways, and enhance activation of insulin signaling [23]. Further, it is reported that in the fed steady state, chronic adaptation to long-chain omega-3 PUFA induced greater activation of the Akt-mTOR-S6K1 signaling pathway, suggesting a mechanism for increased insulin activity that induces energy utilization [9]. Finally, the efficiency of feed utilization for BW gain was increased.

The present study found that reducing omega-6:omega-3 FA ratio of growing pigs' diets significantly increased BW due to greater ADG in the sixth week in pigs fed the 5:1 diet compared to pigs fed the 17:1 treatment because of increased energy utilization associated with insulin activity [9] and immune status improvement in this study, which is in agreement with the findings of Duan et 
al., who reported that the BW and ADG of pigs fed the diet with an omega-6:omega-3 PUFA ratio of 5:1 were increased significantly [11]. Upadhaya et al also showed that a lower omega-6:omega-3 PUFA ratio in the diet linearly increased BW and ADG of weanling pigs but did not affect ADFI [24]. Similarly, a significant difference for BW and ADG of piglets was observed in the fourth week in sows fed a lower omega-6: omega-3 PUFA ratio [25]. In contrast, Li et al. suggested that the inclusion of 3\% omega-3 PUFA in the weaner piglet diet did not significantly improve ADG [4]. Other studies also indicated that there were no effects of dietary linseed (containing omega-3 PUFA) on ADG, feed intake or feed efficiency in pigs [26,27]. In addition, Eastwood et al indicated that there were no linear or quadratic effects of dietary flaxseed meal rich omega-3 PUFA at different levels (0, 100, 200, and 300 $\mathrm{g}$ of flaxseed meal $/ \mathrm{kg}$ of diet) on basal BW gain, feed intake or feed efficiency in growing pigs [28]. The inconsistent findings regarding growth performance in pigs could be due to the oversupply of omega-6 PUFA in the diet, different feed ingredients, source of omega-3 PUFA.

The digestibility of DM and $\mathrm{N}$ was unaffected by reducing the omega-6: omega-3 FA ratio apart from a significant increase in energy digestibility. Similarly, Upadhaya et al. reported that reducing the omega-6: omega-3 ratio from 15:1 to 5:1 increased energy digestibility in weanling pigs [24]. In a recent study, finisher pigs fed $0.75 \%$ protected omega-3 FA also did not show improvement in the ATTD of DM and N [6]. However, our results are contrary to the findings of Upadhaya et al., who reported that the digestibility of DM and $\mathrm{N}$ significantly increased in weanling pigs fed the different ratios of omega-6: omega-3 PUFA diets [24]. Cho and Kim also showed that the addition of $1.5 \%$ and $3 \%$ microencapsulated omega-3 FA from linseed oil did not have any effect on the nutrient digestibility of finishing pigs [29]. The conflicting findings among studies may be related to the type of diets, age, and species of animals and the dose of omega-3 FA in the diets.

Low-density lipoprotein is a major carrier of cholesterol from the liver to each tissue. An increase of LDL seems to have an intimate relation to the generation of arteriosclerosis [30]. Therefore, the cholesterol in LDL (hereinafter referred to as 'LDL-cholesterol') is regarded as a risk factor for arteriosclerosis, and ischemic heart disease (coronary arteriosclerotic disease). Thus, the content of LDL-cholesterol is an important indication of diagnosis, therapy and progression of these diseases [30]. In this study, the HDL, triglyceride, and total cholesterol were unaffected in growing pigs fed the diet with different ratios of omega-6: omega-3 FA. However, the LDL concentrations of blood were significantly reduced in pigs fed the diet with omega-6: omega-3 ratio of 5:1. Similar results were reported by other researchers in human nutrition trials. For example, Pan et al., Siri-Tarino, and Avelino et al. reported that the replacement of dietary carbohydrate with PUFA from linseed oil in humans reduced levels of LDL [31-33]. In addition, there were no significant differences observed in HDL and triglyceride concentrations in human [34]. These results are contrary to the findings of Upadhaya et al., who reported a linear increase in HDL-cholesterol concentrations with the reduction in the ratio of omega-6: omega-3 FA in the diets but no difference was found in LDL concentrations among treatments [24]. The finding of a decrease in LDL-cholesterol concentrations with the reduction in the ratio of omega-6: omega-3 FA in the growing pigs in this study may have a beneficial effect on animal health.

The n-3 and n-6 PUFAs are well-known modulators of the inflammatory process. The PUFA have competing roles in inflammatory pathways where ahigh n-3 PUFA intake can reduce the production of proinflammatory eicosanoids derived from n-6 PUFA, partially because n-3 fatty acids are the preferential substrates for enzymes involved in eicosanoid metabolism [35]. Therefore, it is suggested that the balance of n- 6 and n-3 PUFA in the diet may have stronger effects on fecal microflora than individual PUFA [25]. Yin et al. observed a significant effect on fecal E. coli and Lactobacillus counts gestation-lactating sows by altering the omega-6: omega-3 PUFA ratio in the diets [25]. An increased Lactobacilli content under n-3 PUFA consumption and a lower content under n-6 PUFA consumption in fish has also reported [36]. However, in this study, growing pigs fed the diets with different ratios of omega-6:omega-3 FA did not affect the E. coli and Lactobacillus counts as well as fecal gas emission, which is in agreement with the findings of Upadhaya et al., who reported that the E. coli and Lactobacillus 
counts were not affected by altering omega-6:omega-3 FA ratio in the diet of weaner piglets [24]. To the best of our knowledge, the reason for these findings is unknown. However, we hypothesize that the inconsistency in the findings may be due to the type of diets, age and species of animals, and the dose of omega-3 FA in the diet.

\section{Conclusions}

In conclusion, feeding diets with lower omega-6: omega-3 FA ratios have a positive effect on the ADG, energy digestibility, and LDL concentration in plasma of growing pigs. The 5:1 omega-6: omega-3 ratio diet significantly increased BW, ADG, and energy, and decreased LDL concentrations of blood at the end of the experiment. The fecal E. coli and Lactobacillus counts, and fecal gas emission were not affected by altering the omega-6: omega-3 FA ratio in the diets of growing pigs.

Author Contributions: Conceptualization, D.H.N. and I.H.K.; methodology D.H.N. and H.M.Y; software, D.H.N. and H.M.Y.; data curation, D.H.N. and H.M.Y.; writing-original draft preparation, D.H.N.; writing-review and editing, D.H.N.; visualization, D.H.N. and H.M.Y.; supervision, I.H.K. All authors have read and agreed to the published version of the manuscript.

Conflicts of Interest: The authors declare no conflict of interest.

\section{References}

1. Lim, G.P.; Calon, F.; Morihara, T.; Yang, F.; Teter, B.; Ubeda, O.; Salem, N.; Frautschy, S.A.; Cole, G.M. A diet enriched with the omega-3 fatty acid docosahexaenoic acid reduces amyloid burden in an aged Alzheimer mouse model. J. Neurosci. 2005, 25, 3032-3040. [CrossRef]

2. Simopoulos, A.P. Evolutionary aspects of diet, the omega-6/omega-3 ratio and genetic variation: Nutritional implications for chronic diseases. Biomed. Pharmacother. 2006, 60, 502-507. [CrossRef]

3. Liu, Y.L.; Li, D.F.; Gong, L.M.; Yi, G.F.; Gaines, A.M.; Carroll, J.A. Effects of fish oil supplementation on the performance and the immunological, adrenal, and somatotropic responses of weaned pigs after an Escherichia coli lipopolysaccharide challenge1. J. Anim. Sci. 2003, 81, 2758-2765. [CrossRef] [PubMed]

4. Li, Q.; Brendemuhl, J.H.; Jeong, K.C.; Badinga, L. Effects of dietary omega-3 polyunsaturated fatty acids on growth and immune response of weanling pigs. Anim. Feed Sci. Technol. 2014, 56, 7. [CrossRef] [PubMed]

5. Upadhaya, S.D.; Kim, J.C.; Mullan, B.P.; Pluske, J.R.; Kim, I.H. Vitamin E and omega-3 fatty acids independently attenuate plasma concentrations of proinflammatory cytokines and prostaglandin E2 in Escherichia coli lipopolysaccharide-challenged growing-finishing pigs. J. Anim. Sci. 2015, 93, 2926-2934. [CrossRef] [PubMed]

6. Upadhaya, S.D.; Li, T.S.; Kim, I.H. Effects of protected omega-3 fatty acid derived from linseed oil and vitamin $\mathrm{E}$ on growth performance, apparent digestibility, blood characteristics and meat quality of finishing pigs. Anim. Prod. Sci. 2017, 57, 1085-1090. [CrossRef]

7. Eastwood, L.; Leterme, P.; Beaulieu, A.D. Hanging the omega- 6 to omega- 3 fatty acid ratio in sow diets alters serum, colostrum, and milk fatty acid profiles, but has minimal impact on reproductive performance. J. Anim. Sci. 2014, 92, 5567-5582. [CrossRef]

8. Zanini, S.F.; Torres, C.A.A.; Bragagnolo, N.; Turatti, J.M.; Silva, M.G.; Zanini, M.S. Evaluation of the ratio of $\omega 6$ : $\omega 3$ fatty acids and vitamin E levels in the diet on the reproductive performance of cockerels. Arch. Anim. Nutr. 2003, 57, 429-442. [CrossRef]

9. Palmquist, D.L. Omega-3 fatty acids in metabolism, health, and nutrition and for modified animal product foods. Prof. Anim. Sci. 2009, 25, 207-249. [CrossRef]

10. Calder, P.C. $n-3$ Polyunsaturated fatty acids and inflammation: From molecular biology to the clinic. Lipids 2003, 38, 343-352. [CrossRef]

11. Duan, Y.; Li, F.; Li, L.; Fan, J.; Sun, X.; Yin, Y. n-6:n-3 PUFA ratio is involved in regulating lipid metabolism and inflammation in pigs. Br. J. Nutr. 2014, 111, 445-451. [CrossRef] [PubMed]

12. Drevon, C.A. Fatty acids and expression of adipokines. Biochim. Biophys. Acta 2005, 1740, 287-292. [CrossRef] [PubMed]

13. Ferrini, G.; Baucells, M.D.; Esteve-Garcia, E.; Barroeta, A.C. Dietary polyunsaturated fat reduces skin fat as well as abdominal fat in broiler chickens. Poult. Sci. 2008, 87, 528-535. [CrossRef] [PubMed] 
14. Newman, R.E.; Bryden, W.L.; Fleck, E.; Ashes, J.R.; Buttemer, W.A.; Storlien, L.H.; Downing, J.A. Dietary n-3 and n-6 fatty acids alter avian metabolism: Metabolism and abdominal fat deposition. Br. J. Nutr. 2002, 88, 11-18. [CrossRef]

15. Upadhaya, S.D.; Yun, H.M.; Kim, I.H. Influence of low or high density corn and soybean meal-based diets and protease supplementation on growth performance, apparent digestibility, blood characteristics and noxious gas emission of finishing pigs. Anim. Feed Sci. Technol. 2016, 216, 281-287. [CrossRef]

16. Nguyen, D.H.; Lee, K.Y.; Mohammadigheisar, M.; Kim, I.H. Evaluation of the blend of organic acids and medium-chain fatty acids in matrix coating as antibiotic growth promoter alternative on growth performance, nutrient digestibility, blood profiles, excreta microflora, and carcass quality in broilers. Poult. Sci. 2018, 97, 4351-4358. [CrossRef]

17. National Research Council (NRC). Nutrient Requirements of Swine, 11th ed.; National Academy Press: Washington, DC, USA, 2012.

18. AOAC. Official Methods of Analysis, 18th ed.; Association of Official Analytical Chemists: Gaithersburg, MD, USA, 2007.

19. Wang, Y.; Chen, Y.J.; Cho, J.H.; Yoo, J.S.; Huang, Y.; Kim, H.J.; Shin, S.O.; Zhou, T.X.; Kim, I.H. Effect of soybean hull supplementation to finishing pigs on the emission of noxious gases from slurry. Anim. Sci. J. 2009, 80, 316-321. [CrossRef]

20. SAS Institute. SAS User's Guide: Statistics; SAS Institute: Cary, NC, USA, 2001.

21. Borkman, M.; Storlien, L.H.; Pan, D.A.; Jenkins, A.B.; Chisholm, D.J.; Campbell, L.V. The relation between insulin sensitivity and the fatty-acid composition of skeletal-muscle phospholipids. N. Engl. J. Med. 1993, 328, 238-244. [CrossRef]

22. Liu, S.; Baracos, V.E.; Quinney, H.A.; Clandinin, M.T. Dietary omega-3 and polyunsaturated fatty acids modify fatty acyl composition and insulin binding in skeletal-muscle sarcolemma. Biochem. J. 1994, 299, 831-837. [CrossRef]

23. Gingras, A.A.; White, P.J.; Chouinard, P.Y.; Julien, P.; Davis, T.A.; Dombrowski, L.; Couture, Y.; Dubreuil, P.; Myre, A.; Bergeron, K.; et al. Long-chain omega-3 fatty acids regulate bovine whole-body protein metabolism by promoting muscle insulin signalling to the Akt-mTOR-S6K1 pathway and insulin sensitivity. J. Physiol. 2007, 579, 269-284. [CrossRef]

24. Upadhaya, S.D.; Yun, H.M.; Lee, K.Y.; Kim, I.H. Do varied dietary omega-6 to omega-3 ratios affect the performance, nutrient digestibility, immune status and fecal microbiota of weaner pigs? Anim. Prod. Sci. 2019, 59, 236-242. [CrossRef]

25. Yin, J.; Lee, K.Y.; Kim, J.K.; Kim, I.H. Effects of different n-6 to n-3 polyunsaturated fatty acids ratio on reproductive performance, fecal microbiota and nutrient digestibility of gestation-lactating sows and suckling piglets. Anim. Sci. J. 2017, 88, 1744-1752. [CrossRef] [PubMed]

26. Kouba, M.; Enser, M.; Whittington, F.M.; Nute, G.R.; Wood, J.D. Effect of a high-linolenic acid diet on lipogenic enzyme activities, fatty acid composition, and meat quality in the growing pig. J. Anim. Sci. 2003, 81, 1967-1979. [CrossRef] [PubMed]

27. Nguyen, L.Q.; Everts, H.; Beynen, A.C. Influence of dietary linseed, fish and coconut oil on growth performance of growing pigs kept on small holdings in central Vietnam. J. Anim. Physiol. Anim. Nutr. 2004, 88, 204-210. [CrossRef]

28. Eastwood, L.; Kish, P.R.; Beaulieu, A.D.; Leterme, P. Nutritional value of flaxseed meal for swine and its effects on the fatty acid profile of the carcass. J. Anim. Sci. 2009, 87, 3607-3619. [CrossRef]

29. Cho, J.H.; Kim, I.H. Effects of dietary microencapsulated n-3 fatty acid supplementation on growth performance, nutrient digestibility, blood profiles, carcass characteristics and fatty acid compositions in finishing pigs. Asian J. Anim. Vet. Adv. 2013, 8, 703-712.

30. Miki, Y.; Imajo, N.; Koyama, I.; Hanada, T. Wako Pure Chemical Industries Ltd. Measurement of LDL-Cholesterol. U.S. Patent 5,814,472, 29 September 1998.

31. Pan, A.; Yu, D.; Demark-Wahnefried, W.; Franco, O.H.; Lin, X. Meta-analysis of the effects of flaxseed interventions on blood lipids. Am. J. Clin. Nutr. 2009, 90, 288-297. [CrossRef]

32. Siri-Tarino, P.W. Effects of diet on high-density lipoprotein cholesterol. Curr. Atheroscler. Rep. 2011, 13, 453-460. [CrossRef]

33. Avelino, A.P.A.; Oliveira, G.M.; Ferreira, C.C.; Luiz, R.R.; Rosa, G. Additive effect of linseed oil supplementation on the lipid profiles of older adults. Clin. Interv. Aging. 2015, 10, 1679-1685. 
34. Boberg, M.; Vessby, B.; Selinus, I. Effects of Dietary Supplementation with n-6 and n-3 Long-chain Polyunsaturated Fatty Acids on Serum Lipoproteins and Platelet Function in Hypertriglyceridaemic Patients. J. Intern. Med. 1986, 220, 153-160. [CrossRef]

35. Larsson, S.C.; Kumlin, M.; Ingelman-Sundberg, M.; Wolk, A. Dietary long-chain n-3 fatty acids for the prevention of cancer: A review of potential mechanisms. Am. J. Clin. Nutr. 2004, 79, 935-945. [CrossRef] [PubMed]

36. Ringø, E.; Bendiksen, H.R.; Gausen, S.J.; Sundsfjord, A.; Olsen, R.E. The effect of dietary fatty acids on lactic acid bacteria associated with the epithelial mucosa and from fecalia of Arctic charr, Salvelinus alpinus (L.). J. Appl. Microbiol. 1998, 85, 855-864.

(C) 2019 by the authors. Licensee MDPI, Basel, Switzerland. This article is an open access article distributed under the terms and conditions of the Creative Commons Attribution (CC BY) license (http://creativecommons.org/licenses/by/4.0/). 